\title{
Comunicação
}

[Communication]

\section{Farmacodermia em um cão após administração de antibióticos do grupo betalactâmico: relato de caso}

[Pharmacodermia in a dog after administration of beta-lactam antibiotics: case report]

\author{
G.A.S. Aleixo ${ }^{1}$, M.C.O.C. Coelho ${ }^{2}$, L.S.S. Andrade ${ }^{2}$, F.C.L. Maia $^{2}$, A.K.R. Mota ${ }^{2}$, N.S. Guerra ${ }^{2}$, L.K.R.B. \\ Oliveira ${ }^{2}$, C.E.S. Silva ${ }^{2}$, M.A.S. Lacerda ${ }^{2}$ \\ ${ }^{1}$ Aluna de pós-graduação - UFRPE - Bolsista do CNPq - Recife, PE \\ ${ }^{2}$ Departamento de Medicina Veterinária - UFRPE - Recife, PE
}

Define-se como farmacodermia a reação adversa a fármacos que se manifesta na pele, mucosas e anexos, isoladamente ou associada a alterações em outros órgãos ou sistemas (Caballero et al., 2004). A afecção é de rara ocorrência em cães (Sousa et al., 2005). Dentre os sinais dermatológicos apresentados, estão a dermatite esfoliativa, necrólise epidérmica tóxica (NET), urticária, dermatite vesiculobolhosa, angioedema, urticária, eczema e penfigoide bolhoso (Silva e Roselino, 2003).

Devido à grande variedade de apresentações clínicas (Larsson, 2002; Caballero et al., 2004), ao fato de as características da erupção cutânea serem similares à de outras doenças de pele (Nayak e Acharjya, 2008) e também porque, em muitos casos, o paciente é exposto a mais de um fármaco simultaneamente (Festa Neto et al., 1990; Nayak e Acharjya, 2008), o diagnóstico da reação pode ser difícil (Nayak e Acharjya, 2008). Firmado o diagnóstico, a principal medida terapêutica indicada é a suspensão da administração do medicamento (Pérez e Yabor, 2001; Nayak e Acharjya, 2008).

O presente trabalho teve por objetivos relatar a ocorrência da farmacodermia, mais especificamente a NET, em uma cadela após a administração dos antibiótiß̧os -lactâmicos penicilina e cefalexina e descrever os principais aspectos da afecção, do tratamento e prognóstico, por se tratar de uma afecção de rara ocorrência e alta mortalidade.
Uma cadela, sem raça definida, de 11 anos e $25 \mathrm{~kg}$ de peso, foi submetida à ovariossalpingohisterectomia $(\mathrm{OSH})$ em um hospital veterinário escola para tratar uma piometra. Como protocolo pós-operatório, foi receitado cefalexina (Duprat Rio de Janeiro, RJ) na dose de $25 \mathrm{mg} / \mathrm{kg}$, pela via oral (VO), a cada 12 horas, durante sete dias. Após três dias, a proprietária, ao perceber a presença de secreção na ferida cirúrgica, solicitou a visita de um veterinário particular que após exame clínico suspendeu o antibiótico supracitado e prescreveu penicilina $G$ procaína (Vitalfarma - São Sebastião do Paraíso, MG), na dose de 20.000UI/kg pela via subcutânea (SC), a cada 24 horas. Na terceira aplicação do medicamento, o veterinário observou lesões pustulares no dorso do animal, e a paciente apresentava-se inapetente e febril.

Após uma semana, ao retornar para a avaliação pós-operatória e a remoção dos pontos, a proprietária relatou a ocorrência de áreas supuradas no dorso da paciente. Devido aos pelos escuros, foi necessário realizar uma ampla tricotomia da região, para se perceber uma lesão extensa de, aproximadamente, $30 \mathrm{~cm}$ de largura $\mathrm{x}$ $71 \mathrm{~cm}$ de comprimento.

Coletou-se uma amostra de pele para submeter o material a exame histológico, e antes da preparação asséptica da região para realização da biópsia, coletou-se uma amostra da secreção presente na área com um suabe estéril, para análise microbiológica. 
Como cuidados diários da ferida, foram recomendados a lavagem da região com solução fisiológica (Lafepe - Recife, PE) e clorexidine (Riohex - Ind. Farm. Rioquímica - São Paulo, SP) e posterior proteção com gaze e atadura. Receitou-se tratamento antibiótico com ciprofloxacina (Bayer - São Paulo, SP), $15 \mathrm{mg} / \mathrm{kg}$, VO, a cada 12 horas, durante 10 dias, além de omeprazol (omeprazol, manipulado), $1 \mathrm{mg} / \mathrm{kg}$, VO, a cada 24 horas, durante 20 dias, tramadol (Agener, São Paulo, SP), 1mg/kg, VO, a cada 12 horas, durante cinco dias, e fluidoterapia com solução de ringer com lactato (Lafepe - Recife, PE ).

Como as bordas das feridas foram se desprendendo ao longo do tratamento, no local foi indicado o uso de uma pomada à base de fibrinolisina, desoxirribonuclease e cloranfenicol (Pfizer - São Paulo/SP). Entretanto, após sete dias da primeira avaliação pós-cirúrgica (Fig. 1), optou-se pelo debridamento cirúrgico da ferida. Para a intervenção cirúrgica, a paciente foi sedada com 0,2mg/kg de acepromazina (Univet S/A - São Paulo, SP ) pela via intramuscular (IM) e 1mg/kg (IM) de diazepam (Cristália Prod. Quím. Farm. Ltda. - São Paulo, SP). Posteriormente, a indução anestésica foi efetuada com $15 \mathrm{mg} / \mathrm{kg}$ (IM) de quetamina (Vetbrands São Paulo, SP) e a manutenção da anestesia foi realizada com o mesmo fármaco na dose de $2 \mathrm{mg} / \mathrm{kg}$, pela via endovenosa (EV). Durante o debridamento, a região foi exaustivamente lavada com solução fisiológica e solução de clorexidine, e se removeu a pele necrosada. Em seguida, foi aplicada sobre a região uma camada do gel natural de Aloe vera misturado com açúcar, na proporção de 4:2, e a área foi protegida com um curativo compressivo não aderente. Prescreveu-se, para os dias seguintes, antissepsia da região com clorexidine e solução fisiológica, seguida pela aplicação do gel de Aloe Vera com açúcar, a cada 12 horas.

De acordo com Festa Neto et al. (1990) e Silvares et al. (2008), poucos trabalhos científicos sobre farmacodermia foram divulgados na medicina humana. Na veterinária, o número de trabalhos também é escasso, o que revela a importância deste relato de caso. Isso pode ser justificado pelo fato de a doença ser considerada de rara ocorrência, como descrito por Larsson (2002).

Arq. Bras. Med. Vet. Zootec., v.62, n.6, p.1526-1529, 2010
O quadro da paciente foi classificado como grave, pois, segundo Caballero et al. (2004), a afecção severa ameaça a vida e requer internamento, seja pela doença ou pelas complicações que ela pode gerar. Fischer (2003) relatou, ainda, que a gravidade da doença e o consequente risco de morte estão associados à idade e à extensão do descolamento epidérmico. A paciente acometida, de idade avançada, perdeu quantidade considerável de pele, o que reforça a categorização da afecção como grave. A ampla tricotomia da região foi necessária para avaliar o grau de comprometimento da pele, pois os pelos escuros dificultavam a visualização das lesões. Larsson (2002) citou que é provável que algumas farmacodermias passem despercebidas, quando a sintomatologia é discreta, pela dificuldade em evidenciar as lesões por causa da cobertura dos pelos.

A cultura microbiana indicou a presença de Pseudomonas sp., portanto não seria possível suspender a antibioticoterapia sem administrar outro fármaco para combater tal infecção. Rezende et al. (2006) recomendaram tratamento antibiótico na presença de infecção bacteriana secundária, pois as infecções bacterianas secundárias são a principal causa de morte após a perda de pele, resultante de queimaduras extensas, NET e doenças autoimunes.

Segundo o antibiograma, optou-se pelo emprego da ciprofloxacina, uma quinolona, pois algumas das outras opções faziam parte do mesmo grupo farmacológico que ocasionou a farmacodermia, associado ao fato de a ciprofloxacina estar sendo empregada desde o início do tratamento com bom resultado. Fischer (2003) e Nayak e Acharjya (2008) relataram que é fundamental assegurar que o medicamento que irá substituir o agente que ocasionou a reação de hipersensibilidade não seja da mesma classe farmacológica.

Diagnosticou-se NET, doença também conhecida por síndrome de Lyell, por meio da sintomatologia apresentada e de acordo com os resultados alcançados no histopatológico. Segundo Pérez e Yabor (2001), o diagnóstico é baseado no quadro clínico característico da doença, em exames complementares de rotina e, principalmente, no exame histológico. Cabral et al. (2004) também citaram que a confirmação do diagnóstico inclui a biopsia de pele. Ao exame 
histológico, constataram-se ausência da epiderme e, mais internamente, vestígios de tecido conjuntivo de aspecto hialino e, ainda, ausência de núcleos, indicando intensa colagenólise. Próximo ao colágeno, foi observada intensa reação inflamatória constituída, principalmente, por neutrófilos e alguns macrófagos. Estes resultados foram similares aos de Campos (1967), ao descrever que a NET revela necrose das células epiteliais. Ainda, de acordo com Pérez e Yabor (2001), podem ser encontrados muitos neutrófilos, confirmados nos achados aqui descritos.

Em relação às características macroscópicas, Silva e Roselino (2003) revelaram que essa afecção é caracterizada pela necrólise da epiderme, que ocasiona o seu descolamento, o que resulta em uma aparência muito similar àquela provocada por queimaduras. Este aspecto foi observado na paciente em estudo (Fig. 1). Tal descrição confirmou os achados de Campos (1967), que descreveu o aparecimento de regiões de descolamento epidermal.

Em muitos casos, a única maneira de fechar o diagnóstico é o de expor o paciente a um novo contato com o fármaco, como citado por Festa Neto et al. (1990). Esse desafio farmacológico não foi realizado pelo grave quadro clínico apresentado pela paciente, que possivelmente não resistiria a tal procedimento. Segundo Rezende et al. (2006), assim como em outras afecções ocasionadas por reações adversas a fármacos, na NET o diagnóstico é baseado, primordialmente, nos sinais e na história clínica.

O debridamento cirúrgico só foi realizado após sete dias, porque, nas primeiras avaliações, a paciente reagia à palpação da região, indicando que a área ainda poderia ser preservada. Para evitar o trauma à área na fase de reepitelização (após o debridamento cirúrgico) com possível dano do tecido de granulação durante a troca de curativos, aplicou-se gel natural de Aloe Vera e açúcar, procedimento similar ao realizado por Trapp et al. (2005).

O uso da Aloe Vera ou de qualquer produto de uso tópico foi suspenso quando da diminuição da área da lesão, a fim de permitir que o processo cicatricial transcorresse sem interferências externas (Fig. 2).

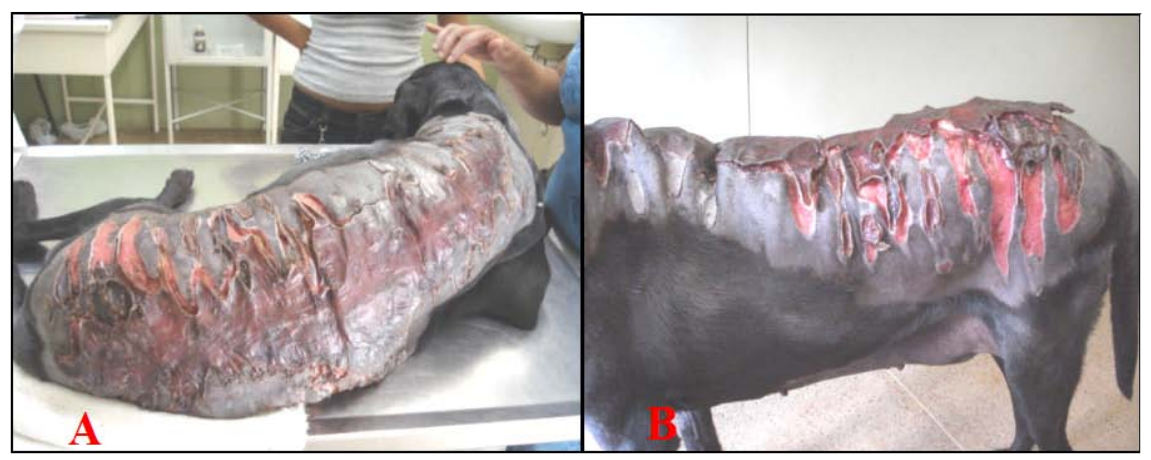

Figura 1. Cão. Aspecto da ferida após sete dias na região dorsal (A) e lateral esquerda (B).

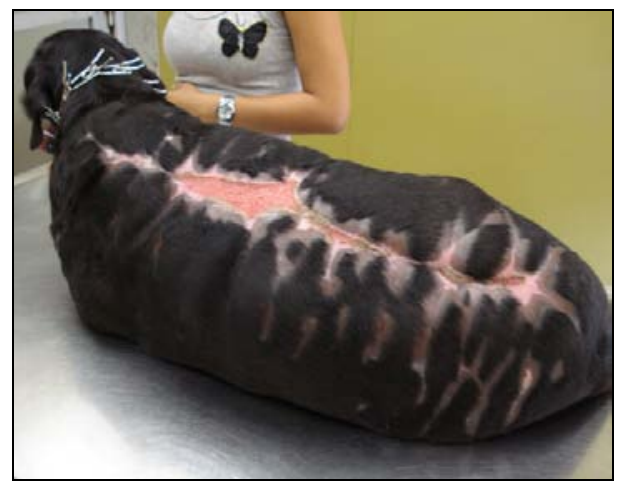

Figura 2. Cão. Evolução da cicatrização com 42 dias. 
Segundo Larsson (2002), os casos de NET, independentemente do tratamento terapêutico instituído, progridem para o óbito. Mesmo sendo considerada uma doença severa e de péssimo prognóstico, a paciente recuperou-se bem, e, em aproximadamente dois meses e meio, toda a área foi completamente preenchida por nova epiderme, diferentemente do caso relatado por Trapp et al. (2005), no qual o cão medicado com trimetoprim e sulfadiazina veio a óbito, três dias após o início do tratamento.

Palavras-chave: cão, fármaco, necrólise epidérmica tóxica, toxidermia

\section{ABSTRACT}

A severe cutaneous reaction in a female dog after administration of penicillin and cephalexin is described, in which the main signs presented by the patient were fever, lack of appetite, and detachment of epidermis in the dorsal region of body. The established treatment was surgical debridement of the region, topical application of Aloe Vera with sugar, and systemic antibiotic therapy with ciprofloxacin, resulting in the recovery and wound closure in approximately 45 days.

Keywords: dog, pharmaco, toxic epidermal necrolysis, toxidermy

\section{REFERÊNCIAS BIBLIOGRÁFICAS}

CABALLERO, A.B.A.; RIVELLI, V.B.; GOROSTIAGA, G. et al. Farmacodermias en niños. Pediatría, v.31, p.112-116, 2004.

CABRAL, L.; DIOGO, C.; RIOBOM, F. et al. Necrólise epidérmica tóxica (Síndrome de Lyell): uma patologia para as unidades de queimados. Acta Med. Port., v.17, p.129-140, 2004.

CAMPOS, E.C. Necrólise epidérmica tóxica Síndrome de Lyell. An. Bras. Dermatol., v.43, p.25-39, 1967.

FESTA NETO, C.F.; FORLANI, L.X.R.; HADDAD, E.S. et al. Farmacodermia - aspectos epidemiológicos, tipos clínicos e agentes casuais. An. Bras. Dermatol, v.65, p.125-128, 1990.

FISCHER, B.C. Farmacodermias no hospital universitário: 5 anos de estudo. 2003. 31f. Monografia (Conclusão de curso de graduação em medicina) - Universidade Federal de Santa Catarina, Florianópolis.

LARSSON, C.E. Drug eruption (DE). In: 27 WSAVA 2002, Granada. Disponível em: $<$ http://www.vin.com/proceedings/Proceedings.p lx?CID=WSAVA2002\&PID=2551/.> Acessado em: 24 set. 2008.
NAYAK, S.; ACHARJYA, B. Adverse cutaneous drug reaction. Indian J. Dermatol., v.53, p.2-8, 2008.

PÉREZ, O.P.; YABOR, V.A. Necrólisis epidérmica tóxica: descripción de 1 caso. Rev. Cuba. Pediat., v.73, p.245-248, 2001.

REZENDE, L.R.C.; PENA, F.M.; SUETH, D.M. et al. Necrólise epidérmica tóxica: relato de caso. Pediatria, v.28, p.199-203, 2006.

SILVA, L.M.; ROSELINO, A.M.F. Reações de hipersensibilidade a drogas (farmacodermia). Res. Med., v.36, p.460-471, 2003.

SILVARES, M.R.C.; ABBADE, L.P.F; LAVEZZO, M. et al. Reações cutâneas desencadeadas por drogas. An. Bras. Dermatol., v.83, p.227-232, 2008.

SOUSA, M.G.; TALIERI, I.C.; JORGE, A.T.B. et al. Reação farmacodérmica decorrente do uso do levamisol: relato de caso. Arq. Bras. Med. Vet. Zootec., v,57, supl.2, p.154-157, 2005.

TRAPP, S.M.: NETA, J.H.; OKANO, W. et al. Farmacodermia associada a reações sistêmicas em um cão pinscher miniatura medicado com a associação de trimetoprim e sulfadiazina. Arq. Cienc. Vet. Zool. Unipar, v.8, p.79-85, 2005. 